\title{
Analisa Pengaruh Perubahan Pitch Ratio dan Jumlah Blade Terhadap Kavitasi Pada Controllable Pitch Propeller (CPP)
}

\author{
Mohammad Danil Arifin ${ }^{1}$, Danny Faturachman ${ }^{1}$, Fanny Octaviani ${ }^{2}$ \\ ${ }^{1}$ Jurusan Teknik Sistem Perkapalan, Fakultas Teknologi Kelautan, Universitas Darma \\ Persada \\ 2 Jurusan Teknik Perkapalan, Fakultas Teknologi Kelautan, Universitas Darma \\ Persada
}

\begin{abstract}
ABSTRAK
Dalam bidang rekayasa kavitasi didefinisikan sebagai proses pembentukan fase uap dari suatu cairan ketika cairan tersebut mengalami penurunan tekanan pada suhu sekeliling (ambient temperature) yang tetap. Kavitasi merupakan fenomena yang merugikan dalam operasinal kapal, karena menyebabkan banyak kerugian. Pengaruh yang merugikan tersebut berupa menurunnya efisiensi propeller, merusak material propeller, kecepatan kapal menjadi lebih rendah dan menyebabkan getaran dan kebisingan. Oleh karena itu dalam penelitian ini dilakukan analisa kavitasi pada Controllable Pitch Propeller (CPP) dengan melakukan variasi jumlah daun yaitu 3,4 dan 5 daun, variasi diameter yaitu 30,40 dan $50 \mathrm{~cm}$, serta variasi pitch yaitu 0.4, 0.6, dan 0.8. Metode yang digunakan dalam penelitian ini adalah metode simulasi. Hasil simulasi menunjukkan bahwa perbedaan putaran propeller memiliki pengaruh terhadap besarnya nilai perbedaan tekanan. Semakin meningkat putaran propeller maka nilai dari perbedaan tekanannya akan semakin meningkat pula. Perbedaan design propeller memiliki pengaruh terhadap area kavitasi yang terjadi pada propeller. Prosentase area kavitasi yang terjadi pada propeller memiki kecenderungan naik pada jumlah blade, putaran serta pitch yang semakin meningkat pula.
\end{abstract}

Keyword: Kavitasi, Controllable Pitch Propeller (CPP), Simulasi, Ambient Temperature, Desain Propeller

\section{PENDAHULUAN}

Propeller adalah jenis baling-baling yang memberikan kekuatan dengan mengubah rotasi gerak dan gaya dorong. Propeller terdiri dari beberapa blade dan beroperasi seperti perputaran sekrup. Propeller pada umumnya diletakkan pada kedudukan serendah mungkin di bagian belakang kapal. Propeller harus mempunyai diameter sedemikian rupa sehingga bila kapal dalam keadaan bermuatan penuh balingbaling dapat terbenam secara memadai sehingga dapat menghindari terjadinya fenomena terikutnya udara (airdrawing) dan pemacuan baling-baling (racing) ketika kapal mengalami gerakan angguk.

Dalam bidang rekayasa kavitasi didefinisikan sebagai proses pembentukan fase uap dari suatu cairan ketika cairan tersebut mengalami penurunan tekanan pada suhu sekeliling yang tetap. Secara umum cairan dikatakan mengalami kavitasi jika di dalam cairan tersebut terlihat adanya gelembung yang terbentuk akibat turunnya tekanan, dalam hal ini tekanan cairan turun dibawah tekanan uap. Untuk dapat memulai timbulnya kavitasi pada tekanan sebesar sekitar tekanan uap diperlukan sejumlah gelembung kecil disebut inti (nuclei), sering hanya dalam ukuran mikroskopis saja, yang mengandung ukuran gas permanen dan atau uap cairan yang bersangkutan. 
Kavitasi menimbulkan kerugian pada operasional kapal, diantaranya timbul bopeng-bopeng pada permukaan punggung propeler yang kemudian menjadi tipis, dapat menyebabkan patah retak, kekasaran punggung sehingga mengurangi efektifitas propeler. Oleh karena itu perlu dilakukan analisa kavitasi pada CPP dengan melakukan variasi desain dari CPP tersebut yaitu dengan melakukan variasi ukuran, putaran serta pitch pada propeller.

\subsection{Perumusan Masalah}

Perumusan masalah di dalam penelitian ini antara lain:

1. Bagaimana kavitasi yang terjadi pada Controllable Pitch Propeller dengan variasi jumlah blade dan pitch.

2. Bagaimana analisa kavitasi pada Controllable Pitch Propeller melalui pendekatan CFD.

\subsection{Batasan Masalah}

Untuk menegaskan dan lebih memfokuskan permasalahan yang akan dianalisa dalam penelitian ini, maka akan dibatasi permasalahan-permasalahan sebagai berikut:

1. Propeler yang akan dianalisa adalah Controllable Pitch Propeller dengan menggunakan 3, 4 dan 5 daun, diameter $30,40,50 \mathrm{~cm}$ dengan variasi pitch yaitu $0.4,0.6,0.8$

2. Pemodelan dilakukan dengan tujuan untuk membandingkan kavitasi hasil konfigurasi model.

3. Analisa data bertujuan untuk mendapatkan hasil akhir berupa pertimbangan konfigurasi paling optimal

\subsection{Tujuan Penelitian}

Berdasarkan permasalahan diatas, penelitian ini bertujuan untuk:

1. Menganalisa kavitasi pada CPP terhadap perubahan kerja pitch dan jumlah blade

2. Menganalisa dan membandingkan kavitasi terhadap perubahan kerja pitch dan jumlah sudut pada CPP melalui pendekatan CFD.

\subsection{Manfaat Penelitian}

Manfaat dari penelitian ini antara lain:

1. Mengetahui kavitasi pada CPP terhadap perubahan kerja pitch dan jumlah blade.

2. Mengetahui perbandingkan kavitasi terhadap perubahan kerja pitch dan jumlah blade pada CPP melalui pendekatan CFD

3. Sebagai bahan referensi untuk penelitian selanjutnya yang berhubungan dengan penelitian ini.

\section{TINJAUAN PUSTAKA}

\subsection{Sistem Propulsi}

Pada saat kapal bergerak dengan kecepatan tertentu, maka akan mengalami gaya hambat dari air, dan untuk mengatasi gaya tersebut diperlukan suatu gaya dorong yang cukup besar dari sistem penggeraknya. Sistem propulsi atau sistem penggerak adalah suatu sistem yang sangat berpengaruh dalam olah gerak kapal. Sistem propulsi kapal terdiri atas komponen:

1. Motor induk (main engine) sebagai penggerak pertama (prime mover)

2. Penggerak (propulsor) 
3. Komponen-komponen transmisi yang meliputi perporosan (shafting), roda gigi reduksi (reduction gear), selain itu juga ada yang menggunakan transmisi listrik (electric transmission)

\subsection{Controllable Pitch Propeller (CPP)}

Controllable Pitch Propeler (CPP) merupakan salah satu perkembangan dari propeler. Controllable Pitch Propeler adalah jenis propeler yang dapat mengubah pitch atau sudut daun propelernya. Sudut daun propeler tersebut nantinya akan disesuaikan dengan kebutuhan kapal. CPP memiliki beberapa keuntungan dibandingkan dengan jenis propeler yang lainnya. Penggunaan CPP (dengan pengubahan pitch) akan memudahkan kita untuk mengubah putaran mesin pada pelayaran dinas yang bertujuan untuk mengurangi getaran dan noise berlebih pada mesin, seperti halnya untuk pitch dapat diubah-ubah untuk mengurangi kavitasi pada berbagai putaran mesin.

\subsection{Hidrodinamika Propeller}

Dalam membuat bentuk dasar propeller dibutuhkan bentuk yang hidrodinamis yang dinamakan hidrofoil dimana menghasilkan suatu lift yang lebih besar dibandingkan dengan drag-nya. Pergerakan dari hidrofoil ini terjadi pada suatu media fluida dengan kecepatan yang memungkinkan terjadinya hidrodinamika. Fluida yang mengalir melalui bagian atas aeofoil melaju lebih cepat daripada fluida yang melewati bagian bawah. Hail ini disebabkan karena adanya perbedaan tekanan antara aliran fluida bagian atas dan aliran fluida bagian bawah. Perbedaan tekanan yang terjadi inilah yang kemudian akhirnya menimbulkan fenomena lift atau gaya angkat itu seperti terlihat pada Gambar 1 dibawah ini:

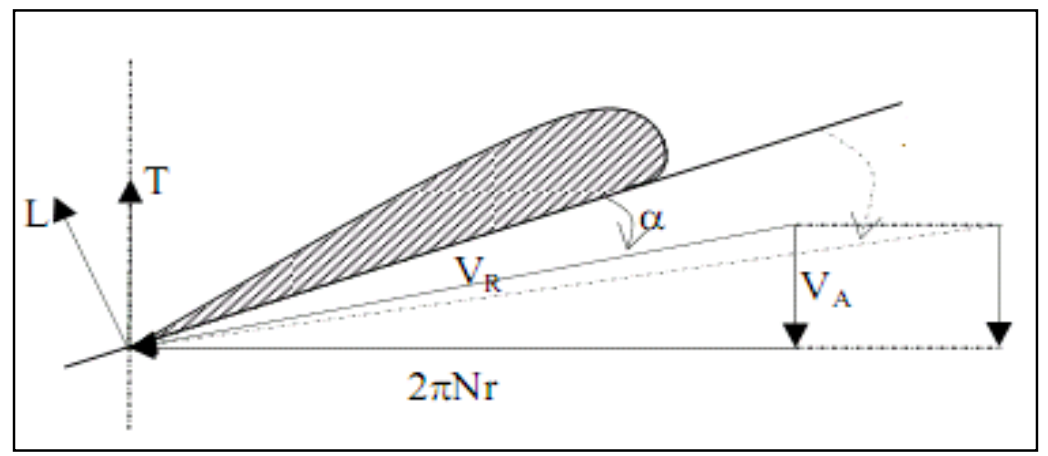

Gambar 1. Gaya angkat pada hidrofoil

\subsection{Persamaan Dasar Dinamika Fluida CFD}

Penerapan pada software yang digunakan, yakni CFD meliputi input-input kondisi fluida yang menjadi media aliran antara lain:

\section{$>$ Boundary Condition Inlet}

Adalah input aliran fluida path kondisi normal tanpa adanya fenomena yang terjadi.

- Massa dan Momentum

Momentum yang terjadi pada aliran fluida yang dipengaruhi oleh massa dan kecepatan dengan vektor kecepatan $\mathrm{U}, \mathrm{V}$ dan $\mathrm{W}$. Arah yang diambil dalam perlakuan terhadap boundary adalah arah normal terhadap domain. Komponen kecepatan aliran (Cartesian Velocity Vector) adalah dengan resultan :

$$
U_{\text {inlet }}=U_{\text {spec }^{j}}+\mathrm{V}_{\text {spec }}{ }^{i}+W_{\text {spec }^{k}}
$$


- Tekanan Total

Tekanan total, plot untuk fluida didefinisikan sebagai :

$$
P_{\text {tot }}=P_{\text {static }}
$$

- Kecepatan Laju Aliran Massa

Batas laju aliran massa, ditentukan sepanjang arah komponen dimana influx massa dihitung menggunakan rumus :

$$
\rho U=m / \int_{s} d A
$$

\section{Boundary Condition Outlet}

- Kecepatan Outlet

Komponen kecepatan outlet boundary adalah komponen cartesian velocity vector

- Tekanan Outlet Fluida

$$
U_{\text {inlet }}=U_{\text {spec }^{i}}+V_{\text {spec }^{j}}+W_{\text {spec }^{k}}
$$

Tekanan outlet fluida adalah tekanan static inlet ditambah perubahan tekanan yang terjadi

$$
P_{\text {tot }}=P_{\text {static }}+\frac{1}{2} \rho U^{2}
$$

\section{Boundary Condition Wall}

- Walk Relative Static Pressure adalah:

Pav = PdA A $\int$ PdA

- Mass Flow Rate Out

Distribusi massa di daerah wall ditentukan oleh aliran berat massa :

$\mathrm{m}=\mathrm{p} \mathrm{A}$, dimana nilai $\mathrm{F}$ dihitung sehingga $\mathrm{M}$ tot $=\sum_{\text {all }} \mathrm{m}$

Dan gaya adalah jumlah adri seluruh aliran massa pada wall boundary. Sehingga

$\mathrm{F}$ dapat digunakan sebagai berikut :

$$
\mathrm{F}=\mathrm{PdA}
$$

\subsection{Kavitasi}

Kavitasi didefinisikan sebagai proses pembentukan fase uap dari suatu cairan ketika cairan tersebut mengalami pengurangan tekanan pada suhu keliling (ambient temperature) yang tetap. Secara umum suatu cairan dikatakan mengalami kavitasi jika didalam cairan tersebut terlihat adanya gelembung yang terbentuk akibat turunnya tekanan.

Banyak penyebab yang dapat menimbulkan kavitasi. Contoh yang paling umum mengenai kavitasi adalah air yang mendidih. Dalam air yang mendidih tekanan uap naik akibat naiknya suhu air. Dalam hidrodinamika kelautan kavitasi umumnya disebabkan karena aliran. Aliran kavitasi demikian itu merupakan aliran dua fase yang terdiri dari cairan dan uap cairan itu, dan transisi fase tersebut ditimbulkan karena perubahan tekanan hidrodinamis

Gambar 2 dibawah ini menunjukkan mekanisme kavitasi. Sebuah penanmpang daun ataun foil udara diletakkan pada sudut pukul yang kecil didalam aliran dua dimensi yang tunak dan tanpa kekentalan. Jauh di depan penampang ini, kecepatan tunak dan seragam tersebut dianggap $U_{0}$ dan tekanan totalnya $p_{0}$. Untuk suatu garis aliran khusus teori bernoulli memberikan 


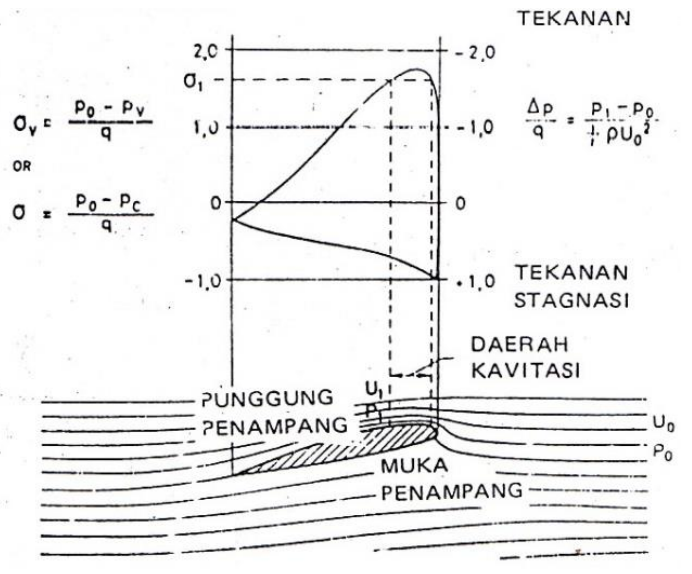

Gambar 2. Aliran dan tekanan disekeliling foil udara

$$
\rho_{0}+1 / 2 \rho U_{0}=\text { tetap }
$$

Karena itu, di titik manapun digaris aliran tersebut barlaku persamaan berikut ini p1 dan $U_{1}$ adalah tekanan dan kecepatan di titik itu:

$$
\rho_{0}+1 / 2 \rho U_{1}^{2}=\rho_{0}+1 / 2 \rho U_{0}^{2}
$$

Perubahan tekanan dititik tersebut adalah

$$
\Delta p=p_{1}-p_{0}=1 / 2 \rho\left(U_{0}^{2}-U_{1}^{2}\right)
$$

Jika $U_{1}$ lebih cepat daripada $U_{0}$ maka $p_{1}$ akan lebih kecil daripada $p_{0}$ dan $\Delta p$ akan mempunyai harga yang negatif. Di suatu titik $S$ didepan hidung (nose) penampang tersebut aliran tadi akan terbelah. Fluida yang mengikuti garis aliran yang membelah tersebut akan diputar melalui $90^{\circ}$, dan kehilangan seluruh kecepatan serta momentumnya dalam arah menurut gerakannya di sepanjang garis aliran tersebut. Dengan demikian maka di titik $S$ (titik stagnasi) kecepatan $U_{1}$ adalah nol, dan

$$
\Delta p=p_{1}-p_{0}=1 / 2 \rho U_{0}^{2}=q
$$

Dimana $q$ adalah aliran stagnasi aliran tersebut.Tekanan dititik pada punggung daun adalah :

$$
p_{1}=p_{0}+1 / 2 \rho\left(U_{0}^{2}-U_{1}^{2}\right)=p_{0}+\Delta p
$$

Dengan demikian maka $p 1$ akan menjadi nol jika :

$$
-p_{0}=\Delta p
$$

Ini berarti bahwa aliran tersebut akan patah dititik itu, mengingat bahwa air tidak dapat menahan tegangan. Gelembung dan rongga kavitasi akan timbul bila

$$
p_{v}=p_{0}+\Delta p
$$


$p v$ adalah tekanan uap air pada saat air mulai mendidih. Karena itu kavitasi akan mulai terjadi bila

$$
\text { dan } \begin{gathered}
-\Delta p>p_{0}-p_{v} \\
\frac{\Delta p}{q}>\frac{p_{0}-p_{v}}{q}=\sigma_{v}
\end{gathered}
$$

$\Delta p$ adalah perubahan tekanan dan merupakan karakteristik geometri aliran $\sigma_{v}$ disebut angka kavitasi uap. Dalam angka ini $p_{0}$ adalah tekanan statis yaitu jumlah dari tekanan hidrostatis dan tekakan atmosfir. Tekanan uap $p v$ tidak tergantung pada suhu. Tekanan stagnasi $q$ tergantung pada massa jenis fluida dan pada kecepatan aliran.

\subsection{Jenis-Jenis Kavitasi}

Laboratorium uji kavitasi membuat sketsa atau memotret pola kavitasi, laboratorium demikian itu sering pula memberikan penjelasan mengenai hasil yang didapat berdasarkan penglihatan mata, yaitu kavitasi uap (cloud), busa (foam), kabut (mist), lembaran (sheet), gelembung, buih (froth), bercak (spot) dan garis (streak) dan sebagainya. Letak kavitasi dapat diterangkan sebagai berikut: Pada ujung daun (tip cativation), kavitasi permukaan (surface cavitation) yang terjadi di dekat ujung daun propeller; kavitasi pusaran (vortex cavitation) yang terjadi di dalam inti tekanan rendah pusaran ujung (tip cortex) propeller. Kavitasi pangkal daun (root cavitation), yaitu kavitasi di dalam daerah tekanan rendah di pangkal daun propeller. Kavitasi Hub atau Pusaran Hub (hub vortex cavitation), yaitu kavitasi di dalam pusaran yang ditimbulkan dari daun propeller pada hub. Selain itu juga ada trailing vortex cavitation, kavitasi punggung (back side cavitation), kavitasi muka (face cavitation) dan kavitasi putaran antara propeller dan badan kapal (propeller hull vortex cavitation)

\section{METODOLOGI}

\subsection{Tahap Awal}

Pada tahap awal ini adalah menentukan perumusan dan pengidentifikasian masalah yang akan dihadapi dimana selanjutnya akan dijadikan acuan untuk menentukan metode penyelesaian yang akan digunakan. Permasalahan yang akan dibahas adalah bagaimana menganalisa kavitasi terhadap perubahan kerja pitch dan jumlah blade pada controllable pitch propeller.

\subsection{Penggambaran Model}

Pembuatan model propeller yaitu menggunakan software. Design propeller dilakukan dengan memvariasikan jumlah blade, diameter, dan pitch propeller. Jumlah blade dari design propeller ini adalah 3, 4 dan 5 daun dengan variasi diameter antara lain 30, 40 dan $50 \mathrm{~cm}$ serta dengan memvariasikan pitch dari propeller yaitu pada pitch 0.4, 0.6 dan 0.8. Berikut adalah hasil visualisasi desain geometri pada software ANSYS. 


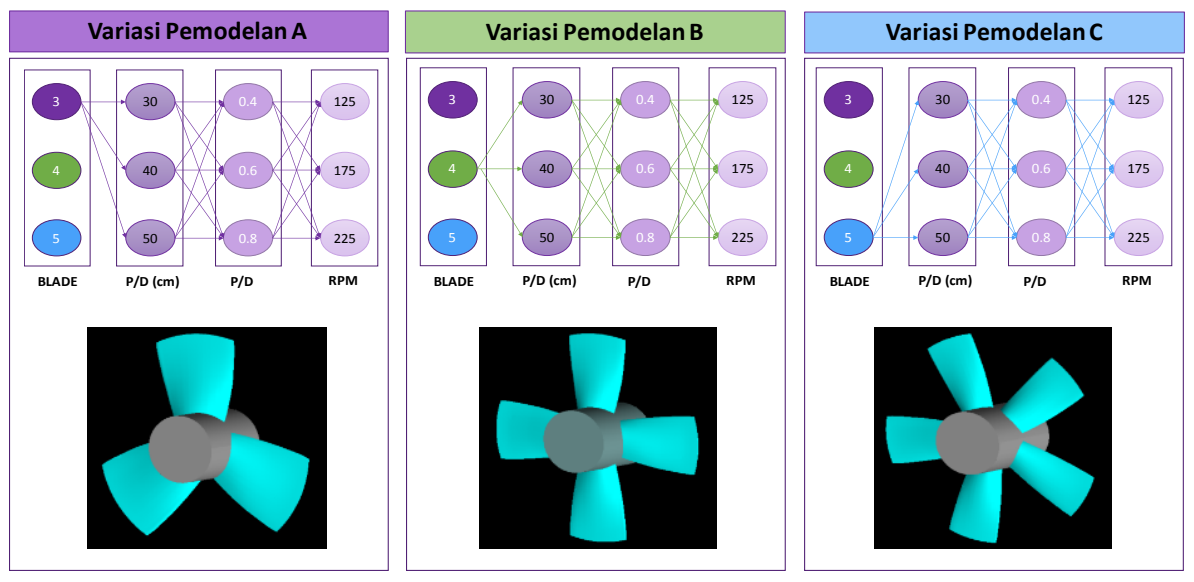

Gambar 3. Geometri propeller dengan 3, 4 dan 5 blade

\subsection{Simulasi Menggunakan CFD}

Model kapal dan propeller yang telah dibuat pada subbab sebelumnya disimulasi dengan menggunakan software CFD. Data yang didapat dari proses simulasi nantinya juga digunakan sebagai validasi dengan menggunakan software yang lain. Ada beberapa langkah yang harus dilakukan dan ditentukan pada proses simulasi dengan menggunakan software CFD ini, yaitu:

\section{Pre-Processor}

Langkah Pre-Processor merupakan langkah awal dimana bahasa pemrograman design modela kan diterjemahkan oleh Solver Manager. Model akan dibentuk sedemikian rupa sehingga terdapat beberapa bagian untuk memberikan batasanbatasan aliran fluida yang dijalankan dan membuat model menjadi suatu objek yang akan dialiri fluida. Dalam hal ini berarti terdapat 2 bagian dalam permodelan dan dibagi menjadi model sebagai objek dan membuat suatu boundary untuk fluida.

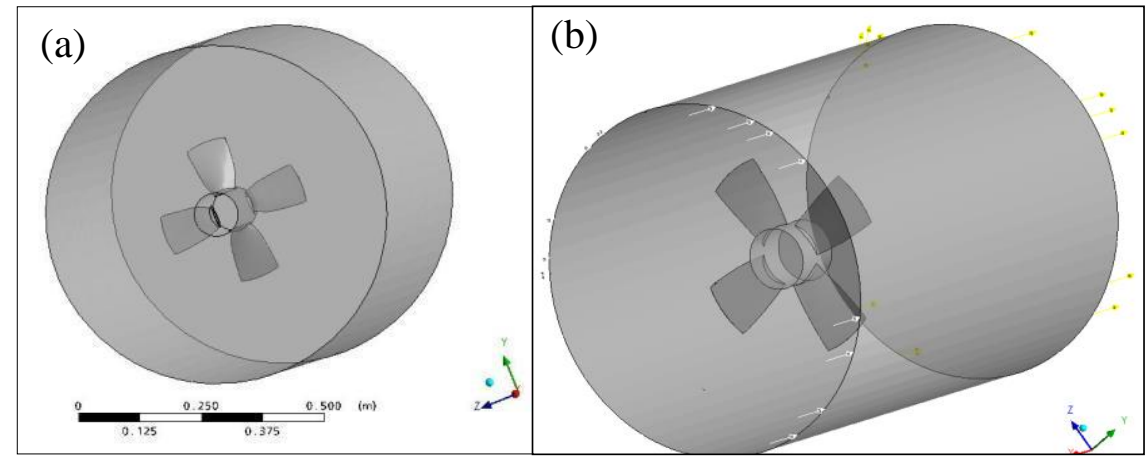

Gambar 4. (a) Objek dan boundary, (b) domain model propeller

Dari dua bagian tersebut objek dan boundary seperti pada Gambar 4(a), kemudian membuat arah aliran fluida yaitu aliran inlet dan outlet sehingga aliran fluida mengenai objek. Objek dapat dikatakan sebagai wall dalam bahasa CFX. Model yang telah dibuat kemudian di import dalam software CFX. Dimana model sebelumnya hanya berupa surface setelah di import ke dalam CFX model dibuat menjadi solid yang kemudian dilakukan meshing. Pada CFX model yang telah jadi dikondisikan sesuai 
dengan kondisi riilnya. Untuk melakukan analisa perlu memasukkan domain-domain atau kondisi yang terjadi pada model seperti pada Gambar 4(b). Domain tersebut antara lain: Jenis fluida, tekanan fluida, temperatur fluida, kecepatan fluida dan jumlah iterasi.

\section{Solver Manager}

Solver manager adalah langkah kedua bagian dari CFX. Dimana pada langkah ini berfungsi sebagai penerjemah file dalam format.def menjadi format.res yang selanjutnya dapat diterjemahkan oleh post-processor.

\section{Post-Processor}

Langkah post-processor akan menampilkan hasil perhitungan yang telah dilakukan pada tahap Solver Manager, hasil perhitungan dapat dilihat berupa data numerik dan data visualis aliran fluida pada model. Data numerik yang diambil adalah data nilai variabel sifat fluida, data sifat fluida.

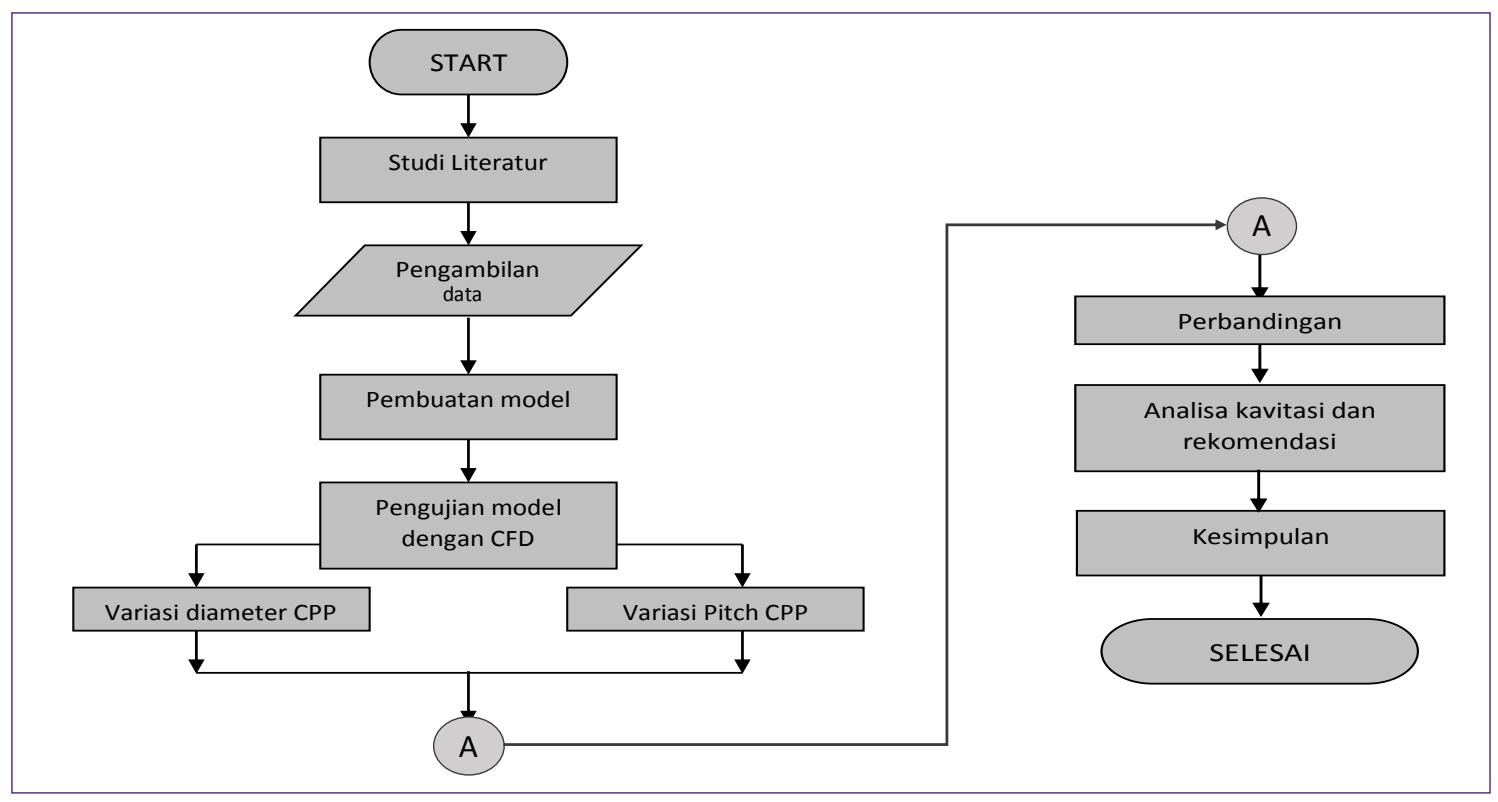

Gambar 5. Flowchart Penelitian

\section{HASIL DAN PEMBAHASAN}

\subsection{Analisa Tekanan Propeller}

Simulasi CFD yang dilakukan pada propeller adalah untuk mengetahui perbedaan tekanan pada sisi face dan back propeller setelah dilakukan beberapa variasi baik diameter, pitch serta putaran pada propeller, dimana CFD dapat menampilkan profil tekanan (pressure). Dari hasil simulasi CFD akan diketahui kecenderungan karakteristik sirip masing-masing design pada variasi putaran yang telah diberikan. Hasil simulasi CFD untuk variasi design propeller untuk analisa tekanan terlihat seperti pada Gambar 6. Gambar ini menunjukkan visualisasi kontur tekanan yang terjadi pada bagian face dan back dari post processor untuk putaran $125 \mathrm{rpm}$ dengan 4 blade. 


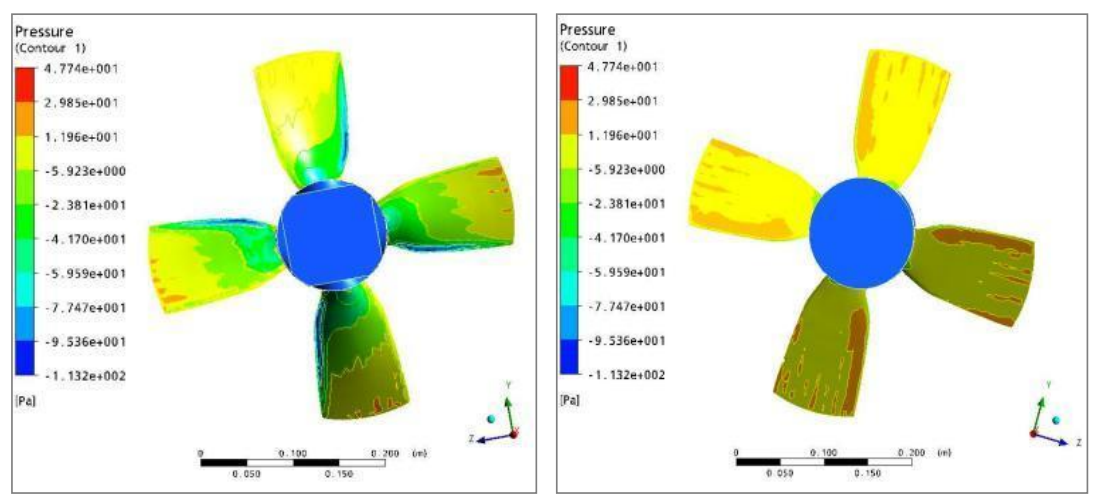

Gambar 6. Kontur tekanan pada face dan back propeller

\subsubsection{Pembahasan Analisa Tekanan}

Berdasarkan simulasi yang telah dilakukan diketahui bahwa besarnya perbedaan tekanan yang terjadi pada propeller mengalami kecenderungan naik pada putaran yang lebih tinggi seperti terlihat pada Gambar $\mathbf{7}$.
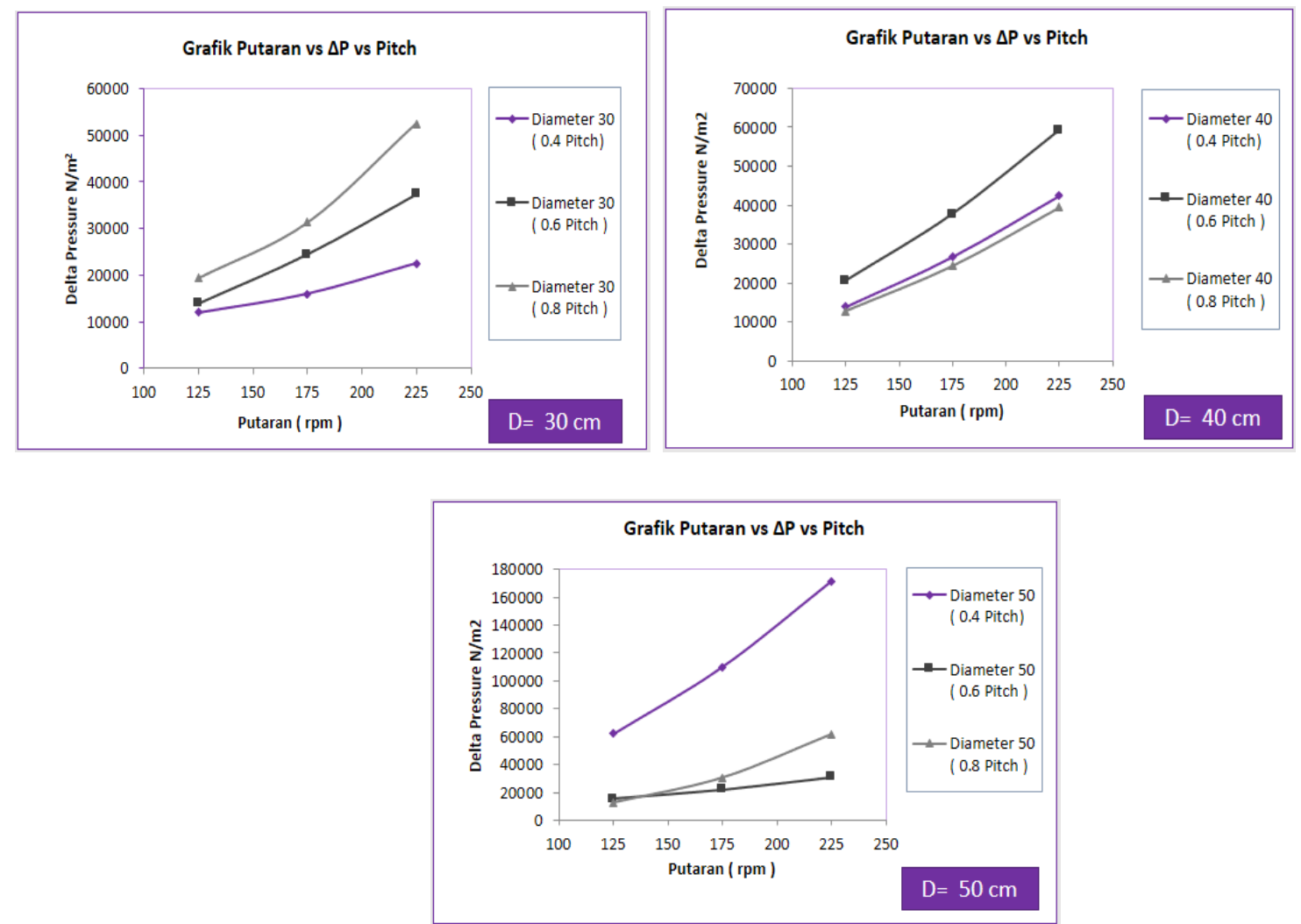

Gambar 7. Grafik perbandingan perbedaan tekanan dengan berbagai variasi

Sebagai contoh pada putaran $125 \mathrm{rpm}$ nilai perbedaan tekanan antara sisi face dan back adalah sebesar $11984 \mathrm{~Pa}$. Untuk putaran $175 \mathrm{rpm}$ nilai perbedaan tekanan antara sisi face dan back adalah sebesar $16000 \mathrm{~Pa}$. Sedangkan pada putaran $225 \mathrm{rpm}$ nilai perbedaan tekanan antara sisi face dan back adalah sebesar $22459 \mathrm{~Pa}$. 
Selain itu besarnya perbedaan tekanan yang terjadi pada propeller mengalami kecenderungan naik pada pitch yang semakin meningkat pada putaran yang tetap. Dimana pada putaran $125 \mathrm{rpm}$ dan pada pitch 0.4 nilai perbedaan tekanan antara sisi face dan back adalah sebesar $11984 \mathrm{~Pa}$. Untuk pitch 0.6 nilai perbedaan tekanan antara sisi face dan back adalah sebesar $13936 \mathrm{~Pa}$. Sedangkan pada picth 0.8 nilai perbedaan tekanan antara sisi face dan back adalah sebesar $19382 \mathrm{~Pa}$, sehingga dapat dikatakan memiliki kecenderungan naik.

\subsection{Analisa Kavitasi Propeller}

Dari hasil simulasi CFD yang telah dilakukan, kita dapat dengan mudah mengetahui kecenderungan karakteristik masing-masing design pada variasi putaran yang telah diberikan. Kavitasi yang terjadi pada propeller dapat diketahui dengan menggunakan menú yang tersedia pada ANSYS yaitu menggunakan isosurface.

Hasil simulasi CFD untuk variasi design propeller (putaran, jumlah blade dan pitch) terhadap kavitasi yang terjadi terlihat pada terlihat seperti pada Gambar 8 dibawah ini. Gambar ini merupakan contoh visualisasi kavitasi yang terjadi pada propeller untuk variasi daun propeller 34 dan 5 blade dengan diameter $300 \mathrm{~mm}$, dan putaran $225 \mathrm{rpm}$.
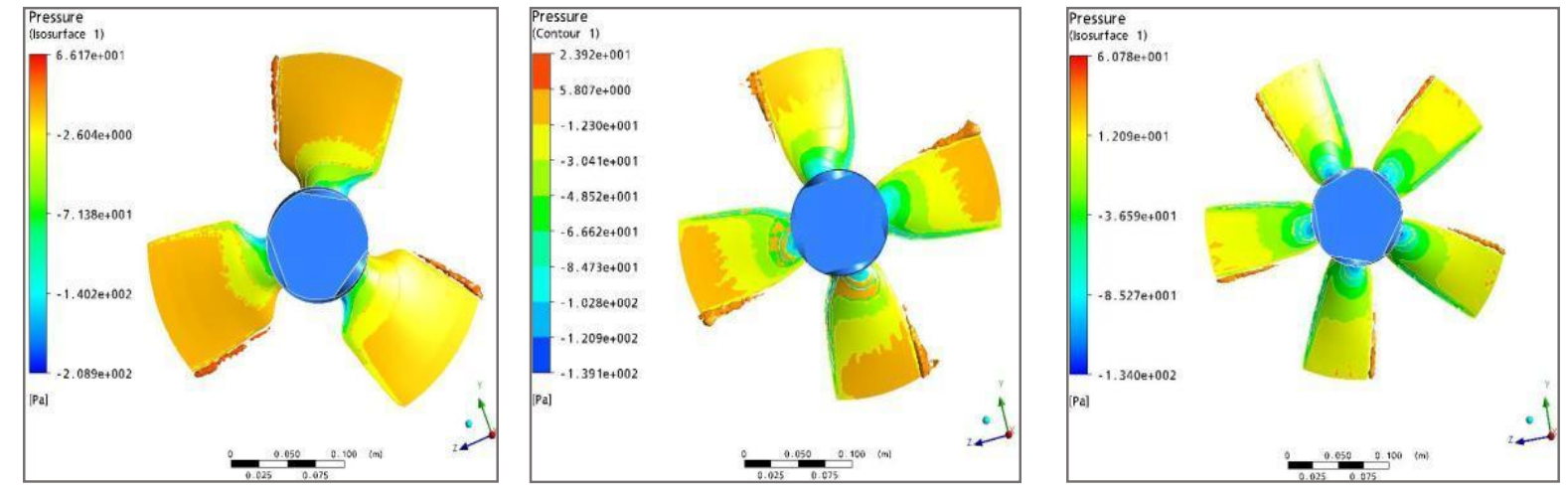

Gambar 8. Area kavitasi propeller 3, 4 dan 5 daun dengan d=300 mm, 225 rpm 225

\subsubsection{Pembahasan Analisa Tekanan}

Berdasarkan simulasi yang telah dilakukan dapat diketahui bahwa besarnya prosentase kavitasi yang terjadi pada propeller dimana kecenderungan naik pada putaran yang lebih tinggi. Hal ini dapat dilihat jelas pada Gambar 9. Misal pada propeller dengan diameter dan jumlah daun serta pitch masing-masing 300 mm, 3 blade dan pitch 0.8 terlihat bahwa pada putaran $125 \mathrm{rpm}$ sama sekali tidak terindikasi terjadinya kavitasi yaitu $0 \%$. Kemudian naik menjadi $1.41 \%$ pada putaran $175 \mathrm{rpm}$ dan semakin meningkat pada putaran 225 menjadi $4.22 \%$ dari luasan total propeller.

Selain itu besarnya prosentase area kavitasi yang terjadi pada propeller mengalami kecenderungan naik pada pitch yang semakin meningkat pada putaran yang tetap. Dimana pada putaran $225 \mathrm{rpm}$ dan pada pitch 0.4 sebesar $3.38 \%$, kemudian naik menjadi $3.85 \%$ pada pitch 0.6 yang kemudian semakin meningkat pada pitch 0.8 yaitu sebesar $4.22 \%$. 

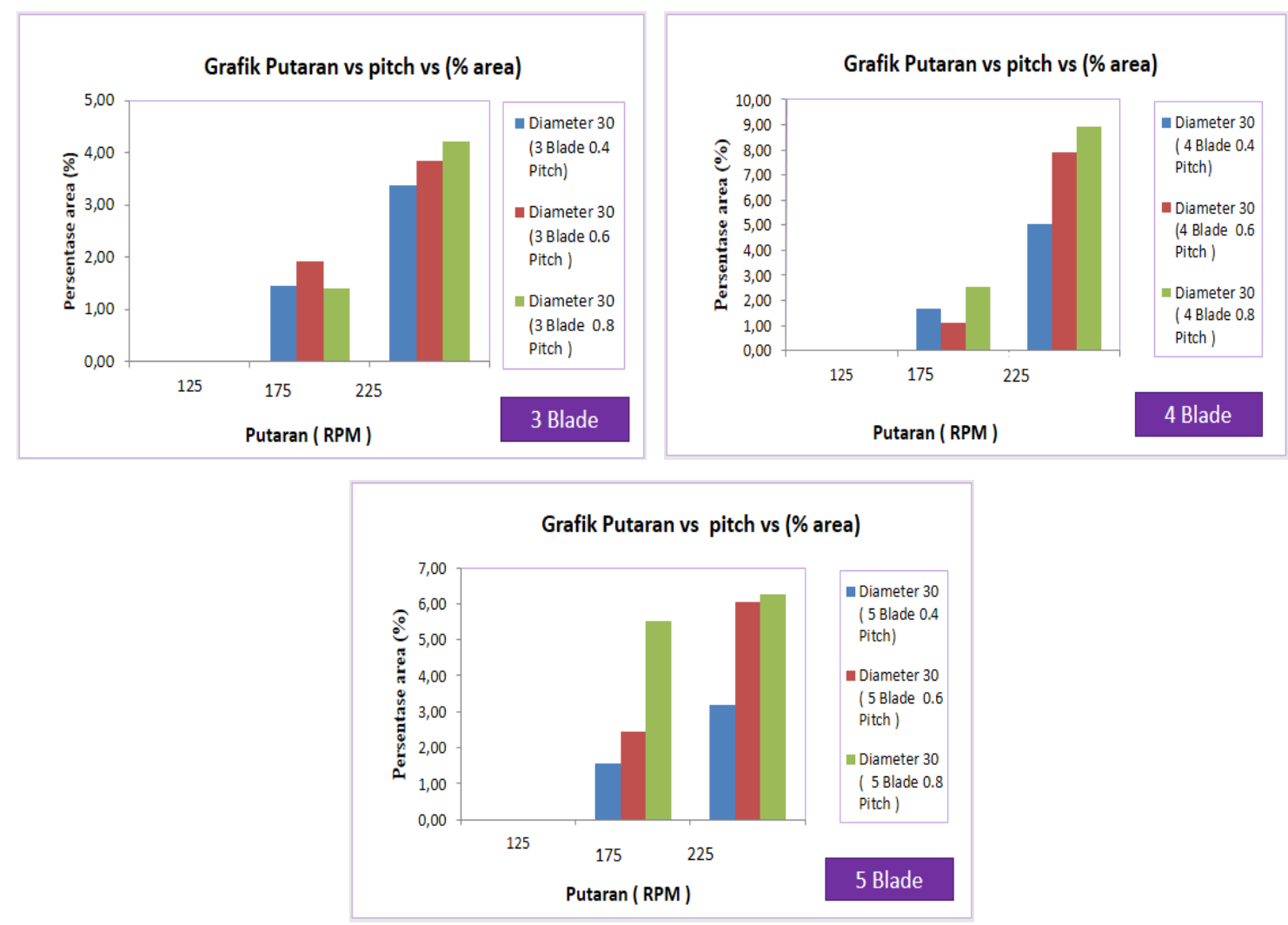

Gambar 9. Grafik perbandingan perbedaan luasan kavitasi dengan berbagai variasi

\section{KESIMPULAN DAN SARAN}

\subsection{Kesimpulan}

Berdasarkan hasil simulasi yang telah dilakukan maka dapat ditarik kesimpulan sbb:

1. Perbedaan putaran propeller memiliki pengaruh terhadap besarnya nilai perbedaan tekanan. Semakin meningkat putaran propeller maka nilai dari perbedaan tekanannya akan semakin meningkat pula. Dimana pada putaran $125 \mathrm{rpm}$ nilai perbedaan tekanan antara sisi face dan back adalah sebesar $11984 \mathrm{~N} / \mathrm{m}^{2}$, kemudian naik menjadi $16000 \mathrm{~N} / \mathrm{m}^{2}$ pada putaran $175 \mathrm{rpm}$ dan semakin meningkat sebesar $22459 \mathrm{~N} / \mathrm{m}^{2}$ pada putaran $225 \mathrm{rpm}$.

2. Perbedaan design propeller memiliki pengaruh terhadap area kavitasi yang terjadi pada propeller. Prosentase area kavitasi yang terjadi pada propeller memiki kecenderungan naik pada jumlah blade, putaran serta pitch yang semakin meningkat pula.

\subsection{Saran}

Untuk memperbaiki ataupun menyempurnakan penelitian selanjutnya, maka penulis memberikan beberapa saran sebagai pertimbangan, antara lain:

1. Type propeller yang digunakan untuk penelitian selanjutnya dapat divariasikan sehingga bisa digunakan untuk perbandingan. 
2. Sebaiknya jumlah iterasi yang diperbanyak sehingga hasil yang didapatkan semakin baik.

\section{DAFTAR PUSTAKA}

1. Adji, S.W, 2001, Tahanan Kapal Diktat Mata Kuliah Propulsi Kapal. JTSP FTK-ITS. Surabaya.

2. Adji, Suryo W. . Propeller Design, Diktat Mata Kuliah Propulsi. JTSP-FTK-ITS

3. Carlton, John, 2007, Marine Propeller and Propulsion, Elsevier, Oxford University

4. Chaosheng Zheng, Dengcheng Liu, and Hongbo Huang, 2019, The Numerical Prediction and Analysis of Propeller Cavitation Benchmark Tests of YUPENG Ship Model, Journal of Marine Science and Engineering. J. Mar. Sci. Eng. 2019, 7, 387; doi:10.3390/jmse7110387

5. Harvald, Sv.Aa, 1992, Tahanan dan Propulsi Kapal, Airlangga University Press, Surabaya

6. Ghose JP, Gokarn RP, 2004, Basic ship propulsion, Allied Publishers Pvt. Limited

7. Kawakita, C. et al., 2012, Prediction of Unsteady Cavitation on Propeller in Consideration of Hull and Rudder Using CFD, Conference proceedings, the Japan Society of Naval Architects and Ocean Engineers, Vol.13 (2011) p.35-38.

8. Kawakita, C. et al., 2012, CFD on Cavitation around Marine Propellers with Energy-Saving Devices", Mitsubishi Heavy Industries Technical Review Vol. 49 No. 1 (March 2012)

9. Lewis, Edward, 1988, Principle of Naval Architecture: Vol I Resistance, Propulsion, The Society of Naval Architects and Marine Engineers. USA

10. Paul Anderson, Jens J. Kappel, Eugen Spangenberg, 2009, Aspects of Propeller Developments for a Submarine, Department

11. Shinagam Rama Krishna et al., 2012, CFD Analysis of a Propeller Flow and Cavitation, International Journal of Computer Applications (0975 - 8887). Volume 55- No.16, October 2012.

12. Sujantoko. . Tahanan \& Propulsi, Hand out untuk Program Pendidikan Tinggi Teknik 1998/1999. FTK-ITS.

13. Tupper, E, 1996, Introduction to Naval Architecture, Butterworth-Heinemann

14. Tutug Triasniwan, 2010, Studi Perancangan Perangkat Lunak Untuk Analisa Identifikasi Kavitasi Pada Propeler, http://digilib.its.ac.id/public/ITSUndergraduate-12495-Paper.pdf

15. www.ansys CFX.com 